\title{
Retraction Note to: Linc-ROR confers gemcitabine resistance to pancreatic cancer cells via inducing autophagy and modulating the miR-124/PTBP1/PKM2 axis
}

\author{
Chenggang $\mathrm{Li}^{1}$ - Zhiming Zhao ${ }^{1}$. Zhipeng Zhou ${ }^{1} \cdot$ Rong Liu $^{1}$
}

Published online: 18 October 2021

(c) Springer-Verlag GmbH Germany, part of Springer Nature 2021

\section{Retraction Note to: \\ Cancer Chemother Pharmacol (2016) 78:1199-1207 https://doi.org/10.1007/s00280-016-3178-4}

The Editor-in-Chief has retracted this article. The corresponding author Chenggang Li informed the journal that the manuscript was submitted by a third party on behalf of the authors. The co-authors Liu Rong, Zhou Zhipeng and Zhao Zhiming stated that they were unaware of the submission and publication of this article. In addition, the authors have been unable to provide documents confirming that ethics approval was obtained for this study. The Editor-in-Chief therefore no longer has confidence in the reliability of this article.

The authors have not responded to correspondence regarding this retraction notice.

Publisher's Note Springer Nature remains neutral with regard to jurisdictional claims in published maps and institutional affiliations.

The original article can be found online at https://doi.org/10.1007/ s00280-016-3178-4.

Chenggang Li

chenggangli@outlook.com

1 Department of Surgical Oncology, Chinese PLA General

Hospital, 28 Fuxing Road, Beijing 100853, China 